\title{
OS TEXTOS NO ENSINO DE PORTUGUÊS LIINGUA ESTRANGEIRA: TEORIAS E PRÁTICAS
}

\section{Florencia MIRANDA*}

- RESUMO: O presente artigo propóe uma reflexão acerca das concepçóes de texto que circulam no ensino de português como língua estrangeira (PLE) e, secundariamente, sobre o lugar dos textos nos materiais didáticos e suas possíveis formas de abordagem. A reflexão parte de uma pesquisa realizada na Universidad Nacional de Rosario, Argentina, e retoma alguns dados significativos que resultam da análise de livros didáticos de PLE. Partindo de uma distinção clássica entre diferentes definiçóes de texto, o artigo mostra qual a concepçáo que predomina nos livros e o lugar que é dado aos textos nesses materiais. Isto é ilustrado a partir de exemplos retirados de livros em uso. A análise realizada permite demonstrar a necessidade de avançar na elaboração de materiais didáticos apoiados em uma concepção de texto mais próxima do estado atual das teorias do texto.

- PALAVRAS-CHAVE: Texto. Português língua estrangeira. Livro didático.

\section{Introdução}

O presente artigo propóe refletir sobre as concepçóes de texto que circulam no ensino de português como língua estrangeira e, secundariamente, sobre o lugar e as formas de abordagem dos textos nos materiais didáticos. Como se sabe, nas últimas décadas a presença dos textos no ensino de línguas estrangeiras tem assumido um papel inquestionável, o que também vem acontecendo com o ensino explícito de gêneros textuais (SCHNEUWLY; DOLZ 2004). Porém, ainda parece existir uma distância significativa entre as propostas dos didatas ou teóricos do ensino e as práticas dos professores em sala de aula. Essa situação demonstra que não basta um conjunto de teóricos proporem algumas mudanças para isso logo acontecer. Daí que seja possível afirmar que as discussóes sobre o lugar dos textos e dos gêneros textuais no ensino de Português Língua Estrangeira (doravante PLE), tal como a implementação de propostas concretas, ainda estão mesmo nos inícios, apesar da enorme e crescente divulgação de trabalhos sobre o assunto.

\footnotetext{
* UNR - Universidad Nacional de Rosario. Facultad de Humanidades y Artes - Escuela de Lenguas. Rosario - Argentina. 2000 - florenciamiranda71@gmail.com
} 
A particularidade deste trabalho é que basearei minhas observaçóes em dados obtidos em uma pesquisa sobre o ensino de gêneros textuais em aulas de PLE, realizada na Universidad Nacional de Rosario, Argentina, no período 20112015. Esse ponto de partida singular permite levantar algumas informaçóes sobre a questão, observando como ela se apresenta em um contexto determinado. Portanto, não se trata aqui de mostrar a situação geral do ensino de PLE, mas sim de identificar alguns aspectos problemáticos a partir de dados reais e não de meras elucubraçóes teóricas.

A pesquisa foi realizada no âmbito do projeto Análisis de géneros textuales para la enseñanza de la lengua extranjera y la traducción (portugués/español) e assumiu como quadro teórico de base o Interacionismo Sociodiscursivo (BRONCKART, 1997, 2008; SCHNEUWLY; DOLZ, 2004; DOLZ et al. 2009). O objetivo foi começar a desenhar instrumentos de consulta destinados a professores (em particular, "modelos didáticos de gêneros" no sentido de De Pietro e Schneuwly (2003)), para a implementação de experiências de ensino de gêneros textuais na aula de português como língua estrangeira para hispanohablantes.

No presente trabalho, retomo os dados coletados na primeira etapa da pesquisa, que teve duas fontes para obter informação: por um lado, questionários e entrevistas a professores e, por outro lado, a análise dos livros didáticos em uso na região próxima à nossa Universidade.

Vale a pena trazer aqui brevemente alguns dos resultados obtidos a partir da aplicação do questionário. Com esse instrumento, verificamos que a maioria dos professores de PLE se formou antes de a noçáo de gênero textual ter entrado no linguajar do campo e em pleno apogeu do enfoque comunicativo. Todos os professores afirmam utilizar um livro didático como base para o planejamento das aulas e consideram importante o trabalho com textos e o ensino de gêneros textuais. A maioria dos docentes indica que para o trabalho com textos e/ou gêneros costuma respeitar as instruçóes propostas pelos próprios livros.

A partir dos questionários foi possível também selecionar o corpus de livros didáticos que devíamos analisar para compreender que propostas de trabalho "textual" predominam no ensino de PLE. No presente trabalho observo especialmente qual a noção de "texto" que subjaz nos livros didáticos analisados ${ }^{1}$ e proponho uma reflexão crítica sobre o lugar dos textos no ensino de PLE. O objetivo último de meu trabalho é contribuir com alguns elementos para os professores assumirem um atitude crítica face à questão dos textos no ensino; dado que o trabalho docente exige efetuar decisóes didáticas fundamentadas e conscientes. Como é evidente, é o professor quem planeja a aula de língua estrangeira, pois a aula não pode (ou não deve!) ser planejada pelo livro (ou pelos autores dos livros). Nesse sentido, assumo

1 Os livros analisados para o presente trabalho foram: Conhecendo o Brasil, Novo Avenida Brasil, BemVindo, Interagindo em Português e Brasil Intercultural. 
que o professor deve poder explicar por que é que trabalha de determinada maneira e ser capaz de controlar quais as propostas dos livros que decide aproveitar e quais as que escolhe rejeitar ou modificar. Para tanto, um dos aspectos centrais no trabalho didático com textos e/ou com gêneros textuais é poder reconhecer qual a noção de texto que subjaz a cada proposta de atividade didática.

\section{A noção de texto: o ponto de vista dos teóricos}

Para falarmos sobre os textos na aula de PLE é preciso primeiramente explicitar que não existe uma noção de texto estável e universal. De fato, "um texto" não é exatamente a mesma coisa para os teóricos, para os professores de língua, para os alunos, para os produtores de materiais didáticos... Isso porque a definição de texto depende sempre do ponto de vista.

Se observarmos o modo como os teóricos do texto concebem esse objeto, veremos que mesmo para esse coletivo não existe uma concepção única e consensual. Já há muitos anos, em um artigo clássico sobre as perspectivas linguísticas do texto, Conte (1989) identificou três concepçôes diferentes para a noção de texto que aqui organizo em três definiçōes ${ }^{2}$ :

Defniniçáo (a): O texto é um "objeto linguístico", que se define como uma sequência coerente de enunciados ou frases. Esta é uma visão limitada às relações locais ou micro entre enunciados ou frases. Essa concepção está na base das abordagens chamadas de "Análises transfrásticas".

Definiçáo (b): O texto é um "objeto linguístico teórico ou abstrato", definível a partir de um conjunto de critérios (sendo coesão e coerência os critérios fundamentais ${ }^{3}$ ). Nessa perspectiva são observados fenômenos globais (as macroestruturas, por exemplo). O texto é considerado um objeto que pode ser descrito fora de qualquer situação de uso. Esta concepção está na base dos projetos de "Gramáticas textuais".

Definiçấo (c): O texto é um "objeto empírico"; uma unidade da comunicação linguística, que se produz em situaçóes concretas de uso da língua. Nessa

\footnotetext{
2 Existem sínteses em português dessa distinção de Conte, em Koch (2001) e Miranda (2010), por exemplo.

3 Vale a pena notar que a ideia que se defende nessa perspectiva é que um texto é ou não é coerente ou coeso em si mesmo, independentemente do contexto em que se realize.

4 Esses projetos de gramáticas do texto tiveram o auge nos anos 1970 e 1980, mas foram abandonados pelos próprios pesquisadores que os defendiam, porque se mostraram insuficientes para compreender a textualidade ver, por exemplo, o comentário de Van Dijk (1995).
} 
perspectiva é assumida a noção de "texto-em-situação". Esta é a concepção que defendem as chamadas "Teorias do texto".

Para se compreender claramente a diferença entre a definição (b) e a definição (c) convém explicitar melhor a distinção entre "unidade linguística" (abstrata) e "unidade da comunicação linguística" (empírica). Por um lado, no primeiro caso, falamos de um objeto construído de forma exclusiva com recursos de uma determinada língua natural, enquanto no segundo caso o objeto-texto mobiliza necessariamente outras unidades semióticas não verbais (sons, imagens, gestos, etc.). Por outro lado, e mais importante ainda, uma "unidade asbtrata" implica que ela tem um sentido imanente, fora de qualquer contexto. Já quando falamos de um "objeto empírico", o sentido é produzido pela relação entre o texto e o contexto. Cabe explicitar que a noçáo de contexto também varia de acordo com as perspectivas teóricas ${ }^{5}$; porém, apesar das diferenças teórico-epistemológicas, o "contexto" pode ser definido como o ambiente natural e social em que a produção do texto se realiza, incluindo basicamente o/s produtor/es do texto, o/s receptor/ es, as coordenadas temporais e espaciais, o âmbito social em que a comunicação se desenvolve e os papéis enunciativos assumidos pelos participantes da interação (enunciador/destinatário).

As três definiçōes apresentadas acima (e as três concepçóes subjacentes) são diferentes e implicam critérios diversos de identificação de um texto. Para quem assume a definição (a), é suficiente existir uma sequência de frases para estarmos perante um texto. Assim, um exemplo de texto poderia ser o seguinte:

\section{Exemplo 1}

Quando eu era adolescente, todo fim de semana eu me encontrava com o pessoal do bairro e a gente armava a maior festa. E quando um de nós fazia aniversário...

Nesse exemplo, vemos uma sucessão de frases que mantêm certos vínculos linguísticos, garantindo a ligação entre elas. Assim, por exemplo, o tempo verbal se mantém no pretérito imperfeito e as formas pronominais da primeira pessoa criam uma série que vai do singular para o plural (eu - me encontrava com o pessoal - a gente - nós...).

Já para quem assume a definição (b), um texto se caracteriza não apenas por ser uma sucessão de frases que mantêm ligação entre si, mas por constituir uma unidade linguística com uma estrutura global reconhecível, independente de qualquer situação de uso. Assim, por exemplo, o exemplo (2) seria indiscutivelmente um texto:

5 Sobre a noção de contexto, ver, por exemplo, Koch e Elias (2006), Bronckart (1997) e Miranda (2010). 


\section{Exemplo 2}

Quando eu era adolescente, todo fim de semana eu me encontrava com o pessoal do bairro e a gente armava a maior festa. E quando um de nós fazia aniversário...

A gente sempre se reunia na casa de alguém. Depois o grupo se dividia: enquanto alguns iam comprar os salgadinhos e as bebidas, os outros ficavam arrumando a sala.

Depois de tudo pronto, a gente passava a noite inteira se divertindo. Meu irmão mais velho tocava violão muito bem. Eu comandava a batucada. Todo mundo dançava e cantava a noite toda. No outro dia, a gente ainda conseguia acordar cedo para ir jogar futebol na praia.

\section{Adolescente tem energia para tudo, não é?}

Fonte: FUNCEB (2000, p. 86).

Do ponto de vista da definição (b), teríamos em (2) um texto narrativo com um narrador participante que desenvolve o tema das lembranças da adolescência. Como vemos, mesmo fora de qualquer situação comunicativa, é possível identificar um tema, um ponto de vista, uma organização discursiva, etc. Para quem defende esta definição de texto enquanto unidade puramente linguística, a situação de uso concreta (quem produz o texto? Em que condiçóes temporais, espaciais, socioculturais, etc.?) não seria fundamental, mas acessório ou secundário.

Ora, para os teóricos do texto que assumem a definição (c), o objeto apresentado em (2) apenas pode ser considerado um texto se forem conhecidas e levadas em consideração as condições de produção desse objeto linguístico. Assim, um teórico do texto - a diferença de um gramático do texto - não consideraria esse objeto linguístico um texto pelo simples fato de ele estar produzido com os recursos de uma língua, mas pelo fato de ele ser um objeto semiótico empírico, produzido em alguma situação de uso da língua. Nesse sentido, o objeto é um texto não por ele conter uma sucessão de frases ou por ele ter marcas de coesão e coerência, mas por ele ter sido produzido em uma situação de comunicação linguística particular. No caso do texto reproduzido em (2), é preciso sabermos que se trata de um exemplar inventado ad hoc, para ser utilizado como modelo para o ensino de português como língua estrangeira, no âmbito de um livro didático para hispanofalantes. Vejamos a página do livro, reproduzida em (3). 


\section{Exemplo 3}

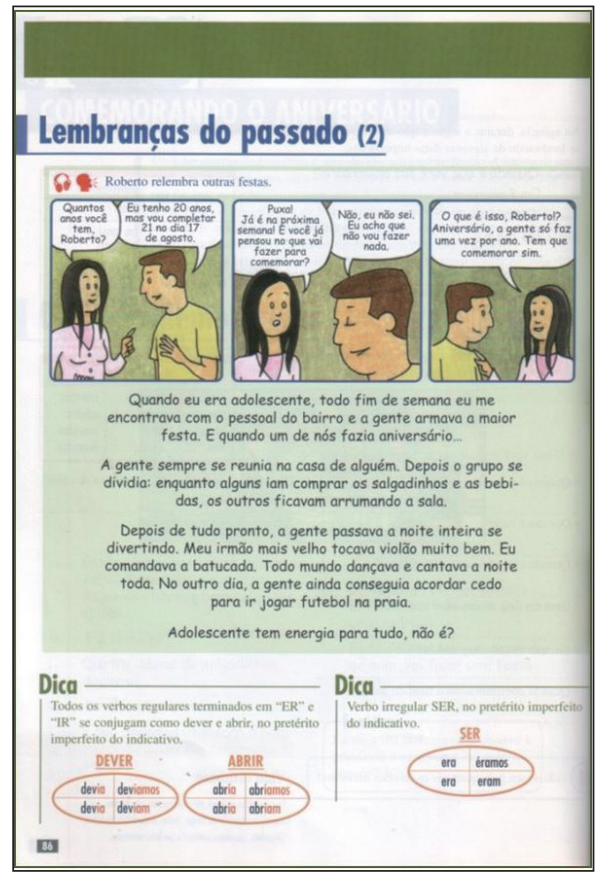

Fonte: FUNCEB (2000, p. 86).

Os três exemplos anteriores mostram um mesmo objeto, porém, submetido ao julgamento de três perspectivas diferentes. Assim, para quem assume a primeira concepção de texto - sequência coerente de frases - ou para quem assume a segunda unidade linguística global e abstrata - o objeto observado é um texto pelos simples fato de ele mostrar uma série ordenada de signos linguísticos, uma estrutura semântica e sintaticamente bem formada. Contudo, para quem assume a terceira concepção - o texto como unidade da comunicação linguística -, esse objeto só pode ser considerado um texto na medida em que se trata de um "exemplo de relato da vida pessoal de alguém simulado em um livro didático". Esses "textos simulados" não constituem um problema em si mesmos - de fato, em toda a história do ensino de línguas maternas ou estrangeiras domina o trabalho com "simulaçóes" -, mas compreender a diferença de concepçáo entre "textos simulados" e "textos reproduzidos", como veremos mais à frente, pode permitir compreender melhor o lugar em que os textos são colocados pelos livros didáticos e pelos professores. Além disso, essa distinção é necessária para o desenho de atividades de compreensão e produção textual, tanto em situação de ensino como em situação de avaliação de conhecimentos.

Convém explicitar desde agora que pessoalmente assumo e defendo a terceira concepção de texto como aquela que se refere efetivamente ao objeto em causa. 
Contudo, não pretendo aqui convencer o leitor das razóes que me levam a adotar esse posicionamento. Também não pretendo contestar aqui quem defende outras concepções. Meu objetivo é mostrar que a noção de texto - como acontece, aliás, com a própria noção de língua - não é estável, rígida e unívoca. Portanto, quando os professores dizem, por exemplo, que consideram importante trabalhar com "textos", não estão dizendo necessariamente que defendem o trabalho com textos "autênticos" - ou textos reproduzidos, com prefiro dizer -. O debate entre utilizar ou não textos autênticos nas aulas de LE já é antigo ${ }^{6}$, mas permanece sempre vigente. Porém, não é esse meu eixo de reflexão. O que quero mostrar aqui é como as diversas concepçóes de texto que acabamos de distinguir ainda convivem e se confundem no campo do ensino de PLE.

\section{Texto(s) nos materiais didáticos de ple: pressupostos e propostas}

$\mathrm{Na}$ análise dos livros didáticos, verificamos que a noção de "texto" não é estável. Baseamos essa afirmação em uma tarefa de nossa pesquisa que foi dedicada a identificar as ocorrências do termo "texto" nos comandos dos livros e a observar as características do exemplar que se estava designando. Assim, observamos que em um mesmo livro podem ocorrer exemplos de configuraçóes linguísticas que constituem de fato um "texto" de acordo com a definição (c) e configuraçóes que só podem ser consideradas como possíveis "simulaçóes de textos" - ou, entáo, "textos" conforme a concepção das definiçōes (a) ou (b). Vejamos alguns exemplos.

O que domina nos livros é a presença de "textos criados ad hoc". Sáo exemplos de possíveis formas de dizer (usar a língua) ou sequências linguísticas sem contexto extralivro. Muitas vezes, essas configuraçôes não se inscrevem em um gênero identificável, como no exemplo (4), mas, eventualmente, parecem simular alguns traços de um certo gênero textual, como nos exemplos (5) e (6).

\section{Exemplo 4}

\begin{tabular}{|c|c|}
\hline $\begin{array}{l}\text { O tempo } \\
\text { Hoje é domingo. O tempo está bonito. } \\
\text { Não está chovendo e não faz frio nem } \\
\text { muito calor. O vento levou as nuvens para } \\
\text { longe e o sol apareceu. Um dia bonito! } \\
\text { Um domingo perfeito! É bom que eu saia. } \\
\text { Quero encontrar alguém que esteja se } \\
\text { sentindo tão bem quanto eu. }\end{array}$ & $\begin{array}{l}\text { E } \\
\bigcirc \text { Tenho que trabalhar. } \\
\bigcirc \text { O tempo está agradável. } \\
\bigcirc \text { Faz sol, mas está frio. } \\
\bigcirc \text { Há nuvens no céu. Vai chover. } \\
\bigcirc \text { Um dia para sair. } \\
\bigcirc \text { Me sinto bem, mas estou sozinho. }\end{array}$ \\
\hline
\end{tabular}

Fonte: Lima, Ishihara e Bergweiler (2010, p.9).

\footnotetext{
6 Sobre a discussão entre o uso de "material autêntico" ou outros materiais, ver os trabalhos clássicos de Widdowson (1991) e de Nunan (1996), ou ainda, no caso das pesquisas no Brasil, Franzoni (1992).
} 
O exemplo (4) reproduz um exercício que visaria a abordar a "compreensão textual". Como vemos, isso que é chamado de "texto" no comando constitui uma sequência de frases (cuja coerência ainda poderia ser discutida) que não apresenta uma unidade pragmática evidente, nem se enquadra em um determinado gênero textual, nem se articula a um contexto de produção reconhecível. A noção de "texto" que subjaz nesse exercício está claramente vinculada à primeira definição que apresentamos no item anterior. Uma sequência (coerente) de frases ganha o estatuto de texto - tal como se explicita no próprio comando do exercício - e pode ser objeto de uma atividade de "compreensão"?

\title{
Exemplo 5
}

\begin{abstract}
Depois de ler o texto, complete a ficha abaixo, com os dados conhecidos. Se quiser inventar os desconhecidos, tudo bem:

Meu nome é Rejane Campos. Há trinta anos, no dia de Natal, eu nasci, aqui em Campinas mesmo. Meus pais, William e Antonieta, ainda moram na Av. Glicério, 12, no centro de Campinas, mas eu estou morando em São Paulo, na Rua Augusta, 10/302, no centro da cidade. O nome de meu noivo é Alberto Morandi. Depois do casamento, vamos morar no meu apartamento atual, que é bom e tem até telefone (5306144). Eu trabalho na Universidade de São Paulo. Sou professora de francês. Na minha sala não tem telefone, mas o da secretaria é 4550982, ramal 203. Meu endereço lá é Caixa Postal 51, Departamento de francês.
\end{abstract}

Fonte: Henriques e Grannier (2001a, p.62).

No caso do exemplo (5), o termo "texto" designa uma unidade linguística global, em que podemos reconhecer uma certa intencionalidade geral (alguém que se apresenta ou fala de si mesmo) e uma unidade temática (os dados pessoais). Isso poderia colaborar na interpretação de que o gênero seria a "apresentação pessoal", por exemplo. Todavia, como exemplar de uma apresentação autêntica esse texto teria informaçóes demasiado detalhadas (por exemplo, a que propósito responderia em uma apresentação verdadeira a menção de tantos números de telefone, endereço, etc.?). De qualquer maneira, não é só por causa da artificialidade, mas pela ausência de indicação de uma fonte original da circulação do texto que sabemos que se trata de uma produção ad hoc. O que vemos aqui é um exercício em que subjaz a definição (b) de texto mencionada acima, dado que se oferece como insumo para uma atividade de reescrita ("completar uma ficha”) uma construção em português produzida para esse efeito, que é independente de qualquer outro contexto de uso. Assim, essa amostra de língua seria considerada um texto pelo fato de ela conformar uma unidade linguística global (e não uma unidade de comunicação).

\footnotetext{
Dado que o objetivo do presente trabalho não é mostrar as fragilidades dos livros didáticos, deixo para futuros artigos uma crítica mais aprofundada da noção de "compreensão textual" que subjaz nos materiais didáticos sistematizados e publicados na forma de livro.
} 


\section{Exemplo 6}

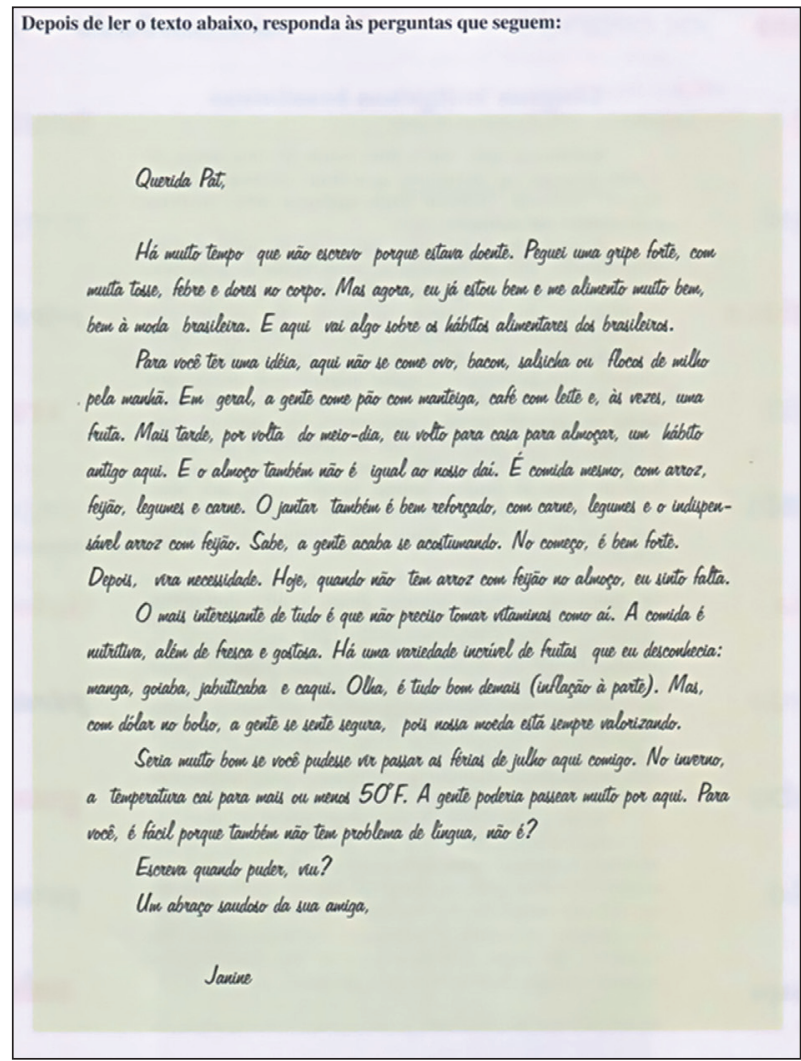

Fonte: Henriques e Grannier (2001b, p.60).

O exemplo (6) também mostra um "texto" entendido como unidade linguística global livre de contexto, mas apresenta traços talvez mais evidentes do que no caso anterior do gênero textual simulado: uma carta. Podemos afirmar isso, sobretudo, por causa do recurso a uma tipografia que imita a escrita à mão e a estruturação global de acordo com o "plano de texto" típico desse gênero (ADAM, 2004, MIRANDA, 2010).

Os exemplos observados até aqui fazem parte de atividades de "compreensão textual" ou de reescrita (ou "retextualização", MARCUSCHI, 2003), mas, como é evidente, a proposta de trabalho com textos nos livros de PLE também diz respeito às capacidades de "produção" textual. Um comentário que vale a pena introduzir aqui é que o termo "texto" nos materiais didáticos analisados só se utiliza nos comandos em que se propóem tarefas de "compreensão e/ou produção escrita". Ou seja, o texto é concebido sempre como uma unidade escrita ou que circula em suporte gráfico.

Nos exemplos (7) e (8) vemos dois casos de atividades de produção textual. Em ambos os comandos é solicitada a escrita de "um texto" sobre um assunto determinado. 
A concepção de texto que subjaz a esses exercícios é inequivocamente a segunda que mencionamos no item anterior: um texto é concebido como uma unidade linguística global, independente de qualquer contexto de produção. Aliás, o contexto seria alguma coisa acessória, secundária, que o aluno eventualmente poderia imaginar para a produção do "texto". O elemento que define a unidade textual seria o conteúdo temático ("hábitos televisivos", no primeiro caso, e "a moeda", no segundo). No exemplo (8) se explicita ainda que o texto deve ser "explicativo".

Convém lembrar que essa classificação do texto como explicativo, narrativo, argumentativo, descritivo, etc. está historicamente vinculada a uma etapa da linguística textual em que a noção de texto era justamente concebida como produto de uma abstração dos parâmetros contextuais (ver, por exemplo, os trabalhos de Adam da década de 1990, tais como Adam (1992, 1999), e para uma discussão, Adam (2001), Koch (2001) e Miranda (2010)).

Esta classe de exercício, muito frequente nos materiais didáticos analisados, parece assumir que a prática de produção textual se limita à escolha de recursos (léxicos, semânticos, sintáticos) de uma dada língua para elaborar um produto isolado de qualquer ambiente sócio-histórico. Assim, pouco parece importar quem escreve, para quem escreve, com que objetivos, em que circunstâncias temporais e espaciais, etc. Ou então, no melhor dos casos, essas decisões ficariam por conta do próprio aluno. É verdade que em ambos os exercícios que mostramos em (7) e (8) o fato de o comando explicitar que o aluno deve escrever sobre uma questáo própria do país dele, traz o pressuposto de que se escreve para um estrangeiro. Porém, será preciso o aluno fazer também outras escolhas em relação ao contexto. Por exemplo, se ele vai escrever mesmo como aluno ou assumindo outro papel enunciativo, se ele vai produzir esse texto como exemplar de um determinado gênero textual socialmente reconhecível ou se a produção se realiza apenas com o modelo da "redação escolar", etc.

\section{Exemplo 7}

\section{Escreva um texto sobre os hábitos televisivos no seu país.}

Como no Brasil, também no/a ... preferem assistir TV sozinhos Ao contrário do Brasil, no meu país... $\quad$ DVDs são mais populares do que TV notícias são populares? assistem TV e leem ao mesmo tempo gos̀tam de assistir TV com amigos assistem muita TV por satélite há/não há propaganda a $T V$ perde espaço para a internetras promas musicais são os preferidos entre jovens $/$ id
reclamam do nível dos programas crianças veem muita/pouca TV

Fonte: Lima, Ishihara e Bergweiler (2010, p.59). 


\section{Exemplo 8}

(3) Escreva um texto explicativo sobre a moeda do seu país. Entre outros aspectos, em seu texto você deve:

- comentar quem são as pessoas ou quais são os símbolos que aparecem nas notas e nas moedas;

- informar quando a moeda começou a serveiculada em seu pais;

- utilizar, pelomenos, cinco palavras aprendidas no exercício 2.

Fonte: Barbosa e Castro (2013a, p.84).

Nos livros analisados não encontramos só "textos simulados" para a abordagem das tarefas de compreensão e/ou produção. De fato, apesar das possíveis dificuldades editoriais para reproduzir textos autênticos (o que muitas vezes tem a ver com os direitos de autor, com problemas técnicos e, finalmente, com obstáculos econômicos) é cada vez mais visível a busca de introdução nos livros de textos variados que circulam socialmente. Esses "textos autênticos" podem ser introduzidos de três formas diferentes: 1) como "textos adaptados" com a indicação da fonte; 2) como "textos reproduzidos" sem a indicação da fonte; 3) como "textos reproduzidos" com indicação da fonte. Os próximos três exemplos mostram essas possibilidades.

Nos três casos, poderíamos assumir que a noção de "texto" que subjaz é a que corresponde à definição (c): o texto-em-situação, o texto enquanto unidade situada da comunicação linguística. No entanto, esses três casos são diferentes entre si, sendo que os dois primeiros ignoram, de certa forma, algum aspecto importante da relação textocontexto. Vejamos melhor cada caso.

$\mathrm{O}$ recurso a textos adaptados (com indicação da fonte) que encontramos no exemplo (9) é uma possibilidade muito explorada no ensino de línguas estrangeiras. Por diferentes razóes (grau de complexidade linguística do texto original, questōes de formatação, extensão, etc.) há autores de materiais didáticos que escolhem adaptar os textos originais e colocar versôes "simplificadas" para os alunos trabalharem. Apesar de que o procedimento de adaptação de textos já foi questionado há muito tempo (ver, por exemplo, Widdowson (1991), essa adaptação ou retextualização efetuada pelo produtor do material pode estar, certamente, bem justificada. Mas um problema sério dessas adaptaçóes pode ser que a distância entre o texto-fonte e o texto-adaptado seja tão grande que já nem se perceba qual o gênero do texto original, qual o contexto de produção desse texto-fonte, nem mesmo qual o conteúdo do texto original. No exemplo (9) podemos ver um caso extremo dessa distância. 


\section{Exemplo 9}

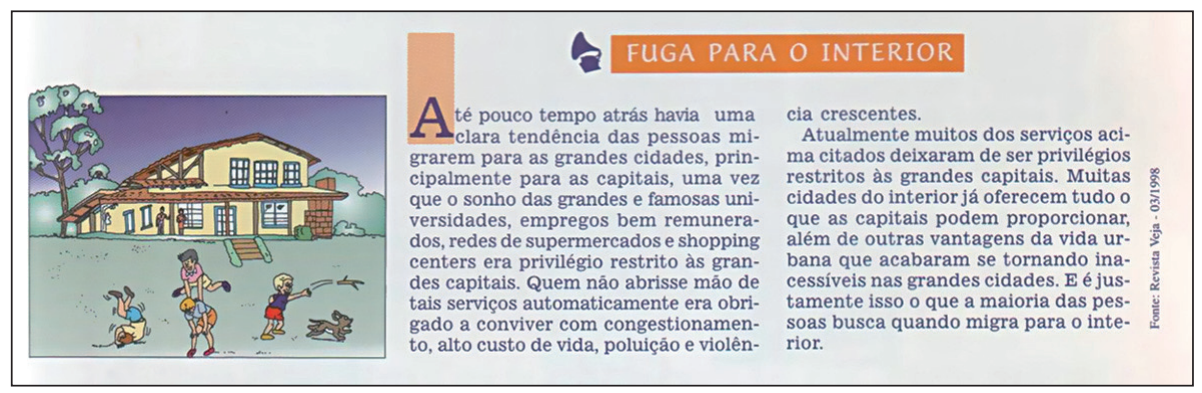

Fonte: Ponce, Burim e Florissi (1999a, p.175).

O texto apresentado no livro indica como fonte uma edição da Revista Veja de 1998. Esse texto tem também uma versão oral (por isso apresenta o símbolo de que existe versão áudio ao lado do título) e no Livro do Professor desse método, Ponce, Burim e Florissi (1999b, p.210), se sugere a seguinte atividade:

"Fuga para o interior": Toque o áudio com o livro fechado e faça perguntas de compreensão, como: "O que, até pouco tempo atrás, era privilégio restrito às grandes capitais?"; "O que mudou?”. Solicite, em seguida, que os alunos leiam o texto em voz alta, uma parte cada um, e, então, trabalhe o vocabulário.

A menção da Revista Veja como fonte não é suficiente para saber qual o texto original que está sendo introduzido no livro e, como vemos, a exploração didática do (novo) texto resulta pobre e descontextualizada. Uma pesquisa rápida pelo acervo digital da revista permite logo verificar que o título do texto adaptado é, na verdade, a manchete da capa dessa edição da revista, enquanto o título do texto-fonte é "A boa vida no interior" - uma escolha claramente diferente, em termos de conteúdo proposicional e de posicionamento enunciativo (já que, por exemplo, no título da versão original do texto citado a "vida no interior" ocorre com um termo axiológico positivo, "boa"). Além disso, o texto-fonte tem uma extensão de sete páginas na revista (da página 70 até a página 76) e inclui muitas imagens e dados. Mais ainda: os dois parágrafos a que fica reduzido a nova versão não reformulam o conteúdo veiculado no texto original, mas alteram esse conteúdo. Mesmo que meu objetivo aqui náo seja comentar ou questionar a metodologia de ensino proposta nos materiais, não posso deixar de me interrogar qual seria a vantagem didática de "simplificar" (deturpar?) um texto, mostrando um par de parágrafos como citação de um outro texto (JUNQUEIRA, 1998).

Em definitiva, o que temos nesse exemplo (9), apesar da indicação de fonte, não é uma reprodução de um texto existente, mas a elaboração de um texto ad hoc, que tem como único contexto possível o próprio material didático. Isto é, apesar de o 
texto se apresentar como retirado de uma fonte outra, a noçăo de texto que aqui se aplica não é a do texto-em-situação, mas a de "objeto linguístico global" (a segunda definição).

Um caso diferente, mas com certa proximidade, é o que vemos no exemplo (10). Aqui se trata (aparentemente, pelo menos!) de um texto reproduzido, mas sem a indicação da fonte.

\section{Exemplo 10}

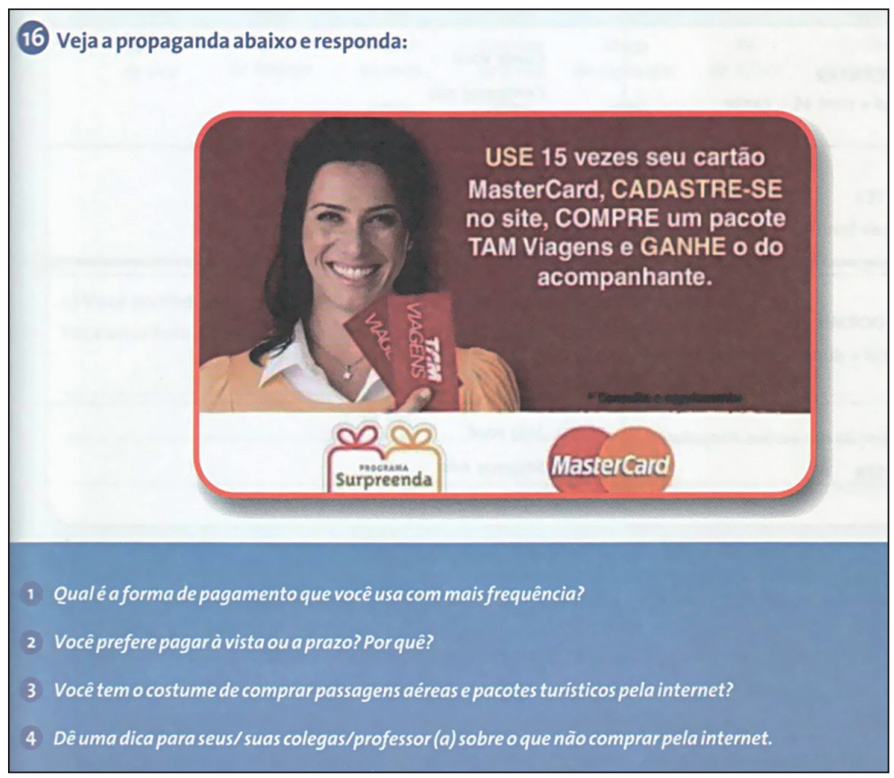

Fonte: Barbosa e Castro (2013a, p.95).

É importante mencionar que, curiosamente, esse exemplo foi retirado de um livro que indica todas as fontes dos textos reproduzidos (geralmente retirados da internet e adaptados). Portanto esse caso parece poder ser explicado como um erro involuntário. Seja como for, a atividade proposta reforça a ideia de que, na realidade, pouco importa o contexto de circulação original do texto reproduzido, uma vez que a partir da leitura das perguntas que se seguem ao texto é possível inferir que seu papel no livro é de mero introdutor do assunto das formas de pagamento (com cartão, à vista, a prazo...). Assim, apesar de que o texto aparenta ser uma unidade da comunicação linguística real reproduzida no livro, acaba funcionando igual que qualquer texto inventado especialmente para o livro. 


\section{Exemplo 11}

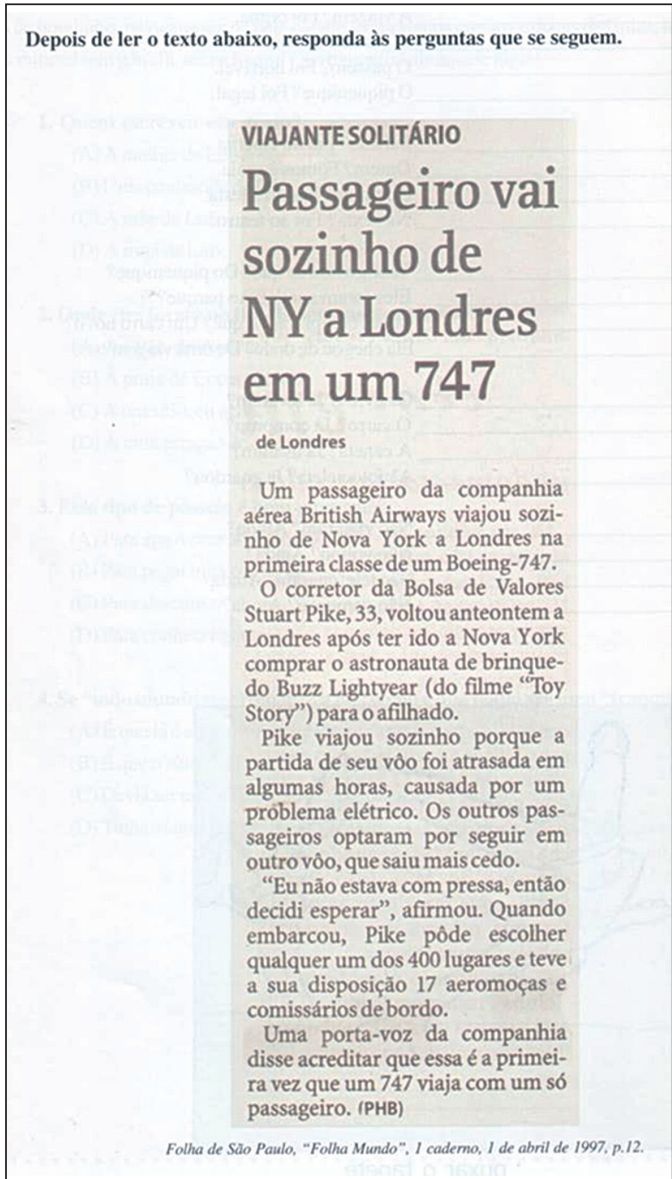

Fonte: Henriques e Grannier (2001b, p.42).

No caso do exemplo (11), o texto é reproduzido no livro respeitando a organização interna, a estrutura e a formatação original (layout, tipografia, conteúdo verbal, etc.) e são indicados os dados completos da fonte ${ }^{8}$. Embora na atividade proposta no livro náo se explore a relação entre texto e contexto de produção/circulação, a reprodução do texto sem alteraçóes mostra vantagens importantes e abre a possibilidade de abordar aspectos que vão além do conteúdo temático central. Nesse caso, por exemplo, seria possível explorar questóes de dêixis temporal (a partir da ocorrência do dêitico "anteontem"), ou mesmo aspectos sociolinguísticos mais complexos, como as mudanças ortográficas recentes (observando a ocorrência do vocábulo voo), entre vários outros aspectos.

8 O texto original pode ser consultado (PASSAGEIRO..., 1997, p.01). 
Contudo, o recurso a textos reproduzidos com indicação de fonte não tem apenas a simples vantagem de abrir a possibilidade a exploraçóes mais ricas e variadas. Aliás, não é esse o aspecto central da importância de se trabalhar com textos reproduzidos. $\mathrm{Na}$ verdade, a relevância do trabalho com textos-em-situação (ou textos contextualizados) é compreender que o texto pode (deve!) ser um objeto de estudo em si mesmo e nem sempre um mero pretexto para trabalhar um conteúdo de gramática, de léxico ou uma dada questão sociocultural. Assim, uma abordagem possível desse texto reproduzido em (11) poderia contemplar também o fato de esse texto ter sido publicado em determinado jornal, para certo público, em uma data específica, etc. Ou seja, a reflexão sobre um texto singular (e, portanto, sobre sua relação com o contexto de produção/ circulação) pode constituir também um conteúdo fundamental em uma aula de português como língua estrangeira.

\section{Abordagens dos textos: caminhos possíveis e decisões do professor}

A análise das concepçôes de texto que subjazem nos livros didáticos nos leva inevitavelmente a refletir também sobre o papel dos textos no ensino de PLE. Mesmo que não tenha sido colocado como objetivo principal, o caminho para a identificação das concepçóes de texto nos mostrou que o lugar dominante dos textos nos materiais didáticos de PLE analisados é aquele de pretexto para o ensino de vocabulário, de conteúdos gramaticais ou de conteúdos socioculturais.

Já vimos uma modalidade desse papel de pretexto no exemplo (10), mas também podemos ver esse papel no exercício clássico de "preencher lacunas de um texto", como em (12).

\section{Exemplo 12}

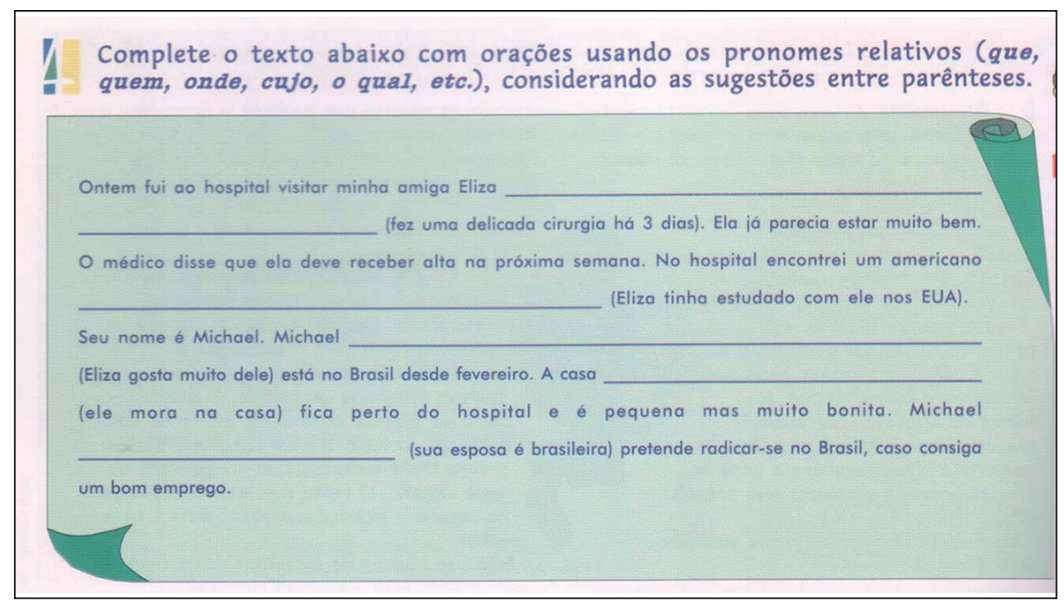

Fonte: Ponce, Burim e Florissi (1999a, p.116). 
É claro que esse lugar está plenamente justificado, já que o ensino de línguas deve partir de pôr os alunos em contato com amostras de língua e as amostras de língua são sempre textos ou fragmentos de textos (reproduzidos, adaptados ou criados ad hoc). De maneira que esse papel de "pretexto" é importante, necessário e insubstituível.

Todavia, a questão que podemos nos colocar é se esse papel é o único que os textos podem desempenhar em nossas aulas. Ou seja, só levamos textos para introduzir conteúdos de natureza lexico-gramatical ou sociocultural? A ideia que defendo é que o lugar de pretexto é apenas um dos lugares possíveis para os textos no ensino de línguas em geral e de PLE em particular. Na análise dos livros didáticos - incluindo os "livros do professor" - verificamos que predomina a ausência de reflexão sobre a singularidade dos textos (sua relaçáo com o contexto, o fato de ele ser um exemplar de um determinado gênero, a análise dos mecanismos de organização interna, etc.).

Como lugar eventual, então, encontramos algum texto que é abordado como objeto de ensino em si mesmo, para aprender a compreender ou a produzir um texto. Um exemplo desse lugar é uma parte da atividade reproduzida em (13).

\section{Exemplo 13}

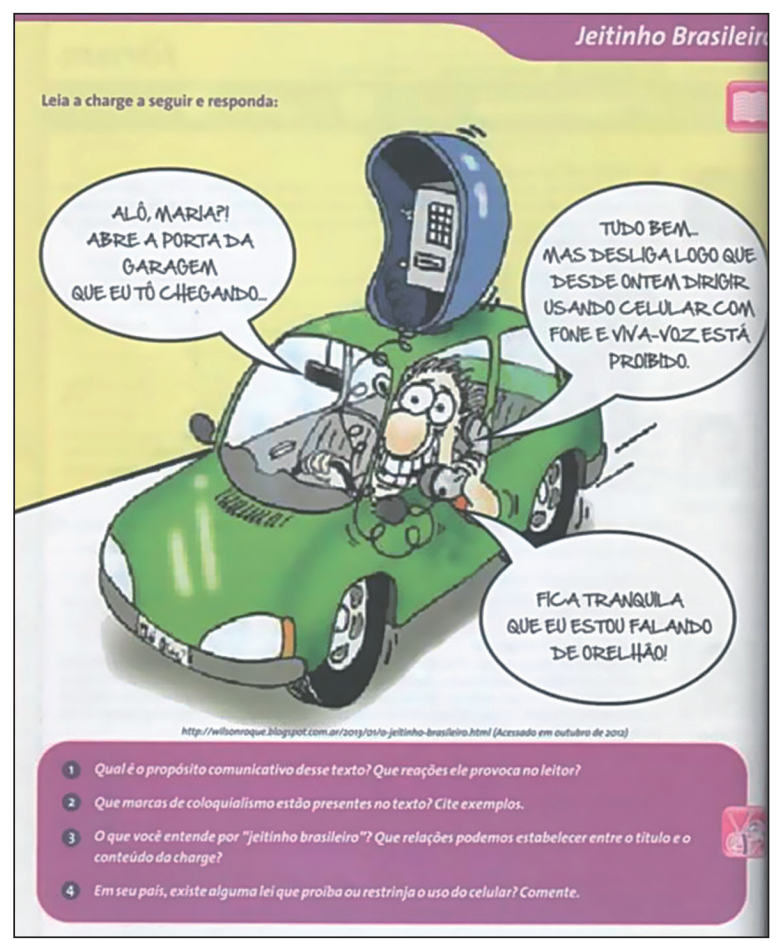

Fonte: Barbosa e Castro (2013b, p.40). 
No exemplo, o texto abre uma unidade sobre o "jeitinho brasileiro" e, de fato, a charge é utilizada como pretexto para introduzir o assunto. Porém, as duas primeiras perguntas colocadas para a exploraçáo do texto mostram uma tentativa de abordar esse objeto na sua singularidade. Vemos uma pergunta sobre o propósito do texto (“Qual é o propósito comunicativo desse texto? Que reaçóes ele provoca no leitor?”), outra sobre o recurso a expressões ou marcas coloquiais ("Que marcas de coloquialismo estão presentes no texto? Cite exemplos") e ainda outra sobre a relaçáo entre o título e o conteúdo da charge ("O que você entende por 'jeitinho brasileiro'? Que relaçóes podemos estabelecer entre o título e o conteúdo da charge?”). Apesar de ser um tratamento extremamente rudimentar, a presença dessas perguntas mostra uma intenção de tentar superar o mero papel de introdutor temático que costumam ter os textos que iniciam unidades nos livros.

\section{Considerações finais}

Segundo os dados obtidos em nossa pesquisa, todos os professores de PLE consultados dizem utilizar um livro como base para o trabalho em sala de aula e a grande maioria dos docentes assume que respeita ou modifica levemente as propostas que esses materiais trazem. Por isso, é fundamental analisar e conhecer seriamente os materiais disponíveis.

A análise de livros didáticos de PLE mostra que, apesar do extenso caminho percorrido pelos teóricos do texto e pelos especialistas em ensino de línguas, nos materiais coexistem concepções diversas e até contraditórias acerca da noção de texto. As concepçôes dominantes nos livros são aquelas (mais antigas) que assumem o texto como "sequência coerente de enunciados ou frases" e como "unidade linguística global que veicula um conteúdo temático com certa estruturação reconhecível (narrativa, argumentativa, descritiva, etc.)". Como concepção eventual, encontramos a noção (mais recente) de "texto-em-situação", ou seja, concebido como "objeto empírico da comunicação linguística".

Face a essa realidade dos materiais didáticos, importa que cada um de nós, professores de PLE, nos perguntemos que noção de texto subjaz a nossa prática. E também, por que, para que e como trabalhamos com textos nas aulas de PLE. Como vimos, basicamente, os textos podem preencher dois espaços principais e náo necessariamente excludentes: por um lado, o texto como pretexto (para ensinar vocabulário, conteúdos gramaticais, conteúdos socioculturais, etc.) e, por outro lado, o texto como objeto de ensino (para desenvolver a capacidade de compreender ou produzir textos; isto é, para saber usar a língua em situações de comunicação). Esse último lugar dos textos no ensino de PLE, e nos livros didáticos analisados em particular, ainda está pouco desenvolvido. Essa constatação mostra que é preciso avançar na elaboração de materiais que se firmem na concepção de texto-em-situação. 


\section{TEXTS IN TEACHING PORTUGUESE FOREIGN LANGUAGE: THEORY AND PRACTICE}

- ABSTRACT: This article proposes a reflection on the text conceptions circulating in teaching Portuguese as a Foreign Language (PLE) and, secondarily, on the place of the texts in teaching materials and possible ways to approach. The reflection part of a survey conducted at the National University of Rosario, Argentina, and incorporates some significant data resulting from the analysis of didactic books of PLE. From a classical distinction between different text settings, the article shows that the conception that prevails in the books and the place that is given to texts in these materials. This is illustrated with examples taken from books in use. The analysis allows to demonstrate the need for progress in the development of teaching materials supported on closer text design of the current state of the text theories.

- KEY-WORDS: Text. Portuguese foreign language. Textbook text.

\section{REFERENCIAS}

ADAM, J. M. Plano de texto. In: CHARAUDEAU, P.; MAINGUENEAU, D. (Org.). Dicionário da análise do discurso. São Paulo: Contexto, 2004. p.377-378.

. En finir avec les types de textes. In: BALLABRIGA, M. Analyse des discours: types et genres: communication et interpretation. Toulouse: EUS, 2001. p.25-43.

Linguistique textuelle: des genres de discours aux textes. Paris: Nathan, 1999.

Les textes: types et prototypes. Paris: Nathan, 1992.

BARBOSA, C. N., CASTRO, G. N. Brasil intercultural: língua e cultura brasileira para estrangeiros. Buenos Aires: Casa do Brasil, 2013a. (Ciclo básico, níveis 1 e 2).

Brasil intercultural: língua e cultura brasileira para estrangeiros. Buenos Aires: Casa do Brasil, 2013b. (Ciclo intermediário, níveis 3 e 4).

BRONCKART, J.-P. Genres de textes, types de discours et "degrés" de langue: hommage à François Rastier. Texto! Textes \& Cultures, [S.1.], v. 13, n.1, p.01-95, 2008. Disponível em: <http://www.revue-texto.net/docannexe/file/86/bronckart_rastier.pdf>. Acesso em: 20 maio 2015 .

Activité langagière, textes et discours: pour un interactionisme socio-discursif. Lausanne: Delachaux et Niestlé, 1997.

CONTE, M. E. La linguistica testuale. Milano: Campi del Sapere/Feltrinelli, 1989.

DE PIETRO, J. F; SCHNEUWLY, B. Le modèle didactique du genre: un concept de l'ingénierie didactique. Les cahiers Théodile, [S.1.], n.3, p.27-52, jan.2003. Disponível em: 
<http://theodile.recherche.univ-lille3.fr/IMG/pdf/Cahiers_Theodile_03.pdf>. Acesso em: 20 maio 2015.

DOLZ, J.; GAGNON, R.; MOSQUERA, S. La didáctica de las lenguas: una disciplina en proceso de construcción. Didáctica, Lengua y Literatura, Madrid, v.21, p.117-141, 2009.

FRANZONI, P. Nos bastidores da comunicaçáo autêntica. Campinas: Ed. da UNICAMP, 1992.

FUNDAÇÃO CENTRO DE ESTUDOS BRASILEIROS [FUNCEB]. Conhecendo o Brasil: curso de português para falantes de espanhol. Buenos Aires: Akian, 2000.

HENRIQUES, E. R.; GRANNIER, D. M. Interagindo em português: textos e visóes do Brasil. Brasília: Thesaurus, 2001a. v.1.

Interagindo em português: textos e visões do Brasil. Brasília: Thesaurus, 2001b. v.2.

JUNQUEIRA, E. A boa vida no interior. Veja, São Paulo, n.1537, p.70-76, 11 mar. 1998. Disponível em: <http://veja.abril.com.br/acervodigital/home.aspx>. Acesso em: 20 maio 2015.

KOCH, I. V. Linguística textual: retrospecto e perspectivas. In: BRAIT, B. (Org.). Estudos enunciativos no Brasil: histórias e perspectivas. Campinas: Pontes, 2001. p.71-86.

KOCH, I. V.; ELIAS, V. M. Ler e compreender os sentidos do texto. São Paulo: Contexto, 2006.

LIMA, E.; ISHIHARA, T.; BERGWEILER, C. Novo avenida Brasil, 3: curso básico de português para estrangeiros. São Paulo: EPU, 2010.

MARCUSCHI, L. A. Da fala para a escrita: atividades de retextualização. São Paulo: Cortez, 2003.

MIRANDA, F. Textos e gêneros em diálogo: uma abordagem linguística da intertextualização. Lisboa: Fundação para a Ciência e a Tecnologia \& Fundação Gulbenkian, 2010.

NUNAN, D. El diseńo de tareas para la classe comunicativa. Madrid: Cambridge University Press, 1996.

PASSAGEIRO vai sozinho de NY a Londres em um 747. Folha de S. Paulo, São Paulo, 01 abr. 1997. Disponível em: <http://acervo.folha.com.br/fsp/1997/04/01/5/>. Acesso em: 20 maio 2015.

PONCE, M. H. O. de; BURIM, S. R. B. A.; FLORISSI, S. Bem-vindo: a língua portuguesa no mundo da comunicação. São Paulo: Special Book Service, 1999a.

Bem-vindo: a língua portuguesa no mundo da comunicação. São Paulo: Special Book Service, 1999b. Livro do professor.

SCHNEUWLY, B.; DOLZ, J. Gêneros orais e escritos na escola. Campinas: Mercado de Letras, 2004. 
VAN DIJK, T. A. De la gramática del texto al análisis crítico del discurso. Boletín de Estudios Linguísticos Argentinos, [S.1.], ano2, n.6, mayo 1995. Disponível em: <http://www. discourses.org/De\%20la\%20gramatica\%20del\%20texto\%20al\%20analisis\%20critico\%20 del\%20discurso.html>. Acesso em: 20 maio 2015.

WIDDOWSON, H. G. O ensino de línguas para a comunicação. Campinas: Pontes, 1991. 